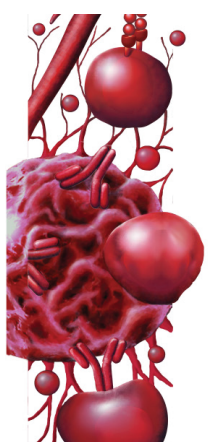

\title{
Is there evidence for anti-TNF drugs in joint involvement in sarcoidosis?
}

A letter in response to: Banse C, Goëb V. Do not forget the joint involvement of sarcoidosis. Immunotherapy 7(6), 599-600 (2015).

Keywords: adalimumab $\bullet$ infliximab $\bullet$ sarcoid arthritis $\bullet$ sarcoidosis $\bullet$ TNF

We read with great interest the letter written by Banse et al. regarding our paper 'AntiTNF therapeutics for the treatment of sarcoidosis' [1]. We agree that musculoskeletal involvement is a very interesting manifestation of sarcoidosis with many questions remaining unanswered. Our review focused on treatment results of anti-TNF drugs in manifestations of sarcoidosis with most published literature. Unfortunately, very little is known on the effect of anti-TNF drugs on musculoskeletal sarcoidosis [2].

The lack of knowledge on the effect of antiTNF drugs in sarcoid arthritis may partly be the result of good response to first- or secondline treatment in patients requiring treatment: studies have reported high response rates up to $100 \%$ to prednisone, NSAIDs or methotrexate in patients with sarcoid arthritis $[3,4]$. Chronic sarcoid arthritis is rare, only occurring in $1-4 \%$ of sarcoidosis patients [5].

We agree with the authors that more research is needed on efficacy of anti-TNF treatment in patients with musculoskeletal involvement in sarcoidosis. However, with our current knowledge anti-TNF drugs should only be used when first- and second-line treatments have failed.

\section{Disclaimer}

The opinions expressed in this article are those of the authors and do not necessarily reflect the views of Future Medicine Ltd.
Financial \& competing interests disclosure The authors have no relevant affiliations or financial involvement with any organization or entity with a financial interest in or financial conflict with the subject matter or materials discussed in the manuscript. This includes employment, consultancies, honoraria, stock ownership or options, expert testimony, grants or patents received or pending, or royalties.

No writing assistance was utilized in the production of this manuscript.

\section{References}

1 Crommelin HA, Vorselaars AD, van Moorsel $\mathrm{CH}$, Korenromp IH, Deneer VH, Grutters JC. Anti-TNF therapeutics for the treatment of sarcoidosis. Immunotherapy 6(10), 1127-1143 (2014).

2 Nessrine A, Zahra AF, Taoufik H. Musculoskeletal involvement in sarcoidosis. J. Bras. Pneumol. 40(2), 175-182 (2014).

3 Visser H, Vos K, Zanelli E et al. Sarcoid arthritis: clinical characteristics, diagnostic aspects, and risk factors. Ann. Rheum. Dis. 61(6), 499-504 (2002).

4 Kaye O, Palazzo E, Grossin M, Bourgeois P, Kahn MF, Malaise MG. Low-dose methotrexate: an effective corticosteroidsparing agent in the musculoskeletal manifestations of sarcoidosis. $\mathrm{Br}$. J. Rheumatol. 34(7), 642-644 (1995).

5 Zisman DA, Shorr AF, Lynch JP. Sarcoidosis involving the musculoskeletal system. Semin. Respir. Crit. Care. Med. 23(6), 555-570 (2002).
Heleen A Crommelin ${ }^{* 1,2}$, Adriane DM Vorselaars', Coline HM van Moorsel', Ingrid HE Korenromp', Vera HM Deneer ${ }^{2}$ \& Jan C Grutters ${ }^{1,3}$ ${ }^{1}$ Centre of Interstitial Lung Diseases, Department of Pulmonology, St Antonius Hospital, Nieuwegein, The Netherlands 2Department of Clinical Pharmacy, St Antonius Hospital, Nieuwegein, The Netherlands ${ }^{3}$ Division of Heart \& Lungs, University Medical Center Utrecht, Utrecht, The Netherlands

*Author for correspondence:

Tel.: +31630788052

Fax: +31883201449

h.crommelin@antoniusziekenhuis.nl
Future
Medicine 